\title{
OPEN Causes of admission, length of stay and outcomes for common kestrels in rehabilitation centres in the Czech Republic
}

\author{
Gabriela Lukesova $^{1 \bowtie}$, Eva Voslarova $^{1}{ }$ Vladimir Vecerek $^{1}$ \& Marijana Vucinic ${ }^{2}$
}

Rehabilitation centres help injured animals to recover and return back to the wild. This study aimed to analyse trends in intake and outcomes for the common kestrels (Falco tinnunculus) admitted into rehabilitation centres in the Czech Republic. From 2010 to 2019, a total of 12,923 kestrels were admitted to 34 rehabilitation centres with an increasing trend $(\mathrm{rSp}=0.7697, P<0.01)$ being found during the monitored period. Subadult kestrels (34.70\%) and kestrels injured by power lines (26.57\%) were most often admitted. Most kestrels in the rehabilitation centres died or had to be euthanized $(81.66 \%)$, only $15.90 \%$ of the birds could be released back into the wild. The median length of stay in rehabilitation centres for kestrels that were subsequently released was 35 days. Considering survival rates, the most critical threat to kestrels was poisoning ( $100 \%$ of the cases resulted in death) but mortality of the kestrels admitted for most other reasons also exceeded $80 \%$. Given the low success rate of the care of kestrels in rehabilitation centres and the relatively small proportion returned to the wild, it is essential to eliminate the causes leading to their admission, that is, to protect their natural habitats and to prevent unnecessary capture.

Raptors (Falconiformes) are a diverse group of birds, however, many of them are endangered species. Eighteen percent of raptors are threatened with extinction and $52 \%$ of raptors have declining global populations ${ }^{1}$. Threats to raptors come primarily from humans and include habitat loss, climate change, poisoning, collisions, electrocutions, deliberate trapping or shooting ${ }^{2-5}$. In result, raptors are often admitted to rehabilitation centres ${ }^{6}$. However, only a few studies focused on the intake and outcomes for raptors at rehabilitations centres so far. Furthermore, they usually have included data for multiple species while total number of birds and rehabilitation centres included in the analyses was very limited. Komnenou et al. ${ }^{6}$ analysed outcomes for 402 raptors from 19 species admitted to the Veterinary Medical Teaching Hospital in Greece during a 3-year period (1997-2000). Harris and Sleeman ${ }^{7}$ analysed medical records from 111 bald eagles and peregrine falcons admitted to the Wildlife Center of Virginia from 1993 to 2003. The release rate reported for raptors in those studies was not high, it ranged from $39 \%{ }^{7}$ to $57 \%^{6}$. Given the limited data analysed, the question remains how effective rehabilitation of raptors is. Our study aimed to assess trends in reasons for admission and treatment outcomes for a single species, namely common kestrel. Data from all rehabilitation centres in the Czech Republic during a 10-year period were collected for analysis. The common kestrel was chosen because this species is widespread in the Czech Republic and in consequence it is the raptor species most frequently admitted into rehabilitation centres. The data on species admitted in low numbers would not allow such a thorough analysis. However, we believe that analysis of reasons of admission and outcomes for common kestrels reflect also the threats faced by other raptors and not only in the Czech Republic. We assessed the most common causes of admission of these animals to rehabilitation centres, time spent in rehabilitation centres and the outcomes of rehabilitation. Furthermore, we analysed mortality rates in birds admitted into rehabilitation centres for different reasons. Knowledge of these factors is important for the protection of animals especially in their natural habitat to mitigate impacts of anthropogenic and other factors, which negatively affect common kestrels in the wild.

The common kestrel (Falco tinnunculus) is a small raptor from the Falconidae family, widespread throughout Europe, large parts of Asia and Africa, and just as abundant in the Czech Republic ${ }^{8}$. It is also known as the European kestrel, Eurasian kestrel or Old World kestrel. According to the International Union for Conservation

${ }^{1}$ Department of Animal Protection and Welfare and Veterinary Public Health, Faculty of Veterinary Hygiene and Ecology, University of Veterinary Sciences Brno, Brno 61242, Czech Republic. ${ }^{2}$ Department of Animal Hygiene, Faculty of Veterinary Medicine, University of Belgrade, 11000 Belgrade, Serbia. ${ }^{\circledR}$ email: lukesovag@vfu.cz 


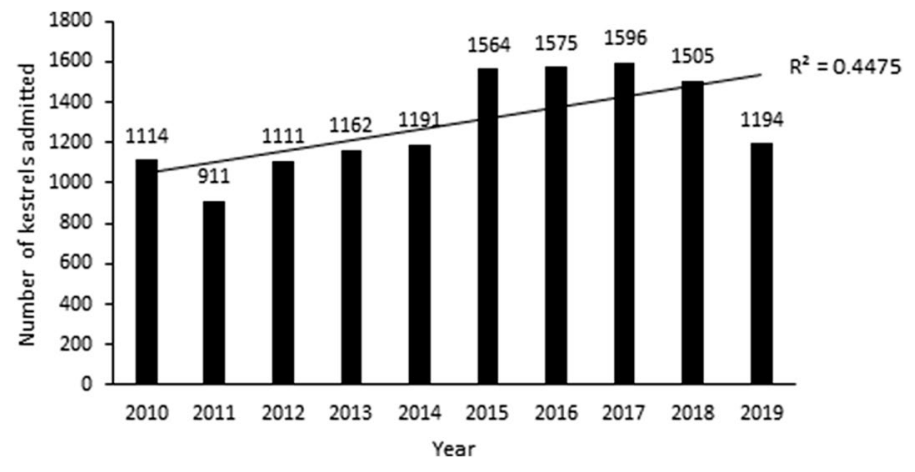

Figure 1. Number of common kestrels admitted to rehabilitation centres in the Czech Republic in the period from 2010 to 2019.

of Nature, the common kestrel is included into the LC (least concern) category, i.e. it is not directly threatened by extinction. However, the International Union for Conservation of Nature, in agreement with some studies, draws attention to the declining trend in the number of these birds ${ }^{9}$. The common kestrel, like many other animal species, is adversely affected by anthropogenic activity. This activity results in deaths and injuries that reduce the common kestrel's quality of life and thus its populations often decline $\mathrm{e}^{10}$. Intensive agriculture also contributes to the decline of common kestrels ${ }^{11}$. In the past, it has been mainly due to the use of certain toxic substances, such as organochlorides and biphenyls ${ }^{12,13}$. In the case of poisoning in raptors, it is also important to mention lead poisoning, caused not only by the use of lead ammunition but by secondary poisoning as well ${ }^{14}$. As anthropogenic activity changes, its effects on kestrel populations may vary over time. For example, in the second half of the twentieth century Newton et al. ${ }^{15}$ described a gradual reduction in mortality of sparrow hawks and kestrels due to organochloride poisoning and gunshots and, conversely, an increase of mortality after colliding with traffic. Similarly, the risks to raptors may vary depending on the habitat they inhabit ${ }^{16}$. Raptors living in the forest are endangered by logging and other species are affected by agriculture ${ }^{1}$. In addition to poisoning, raptors are also frequent victims of collisions with power lines ${ }^{17}$.

Despite the negative effects of anthropogenic activity, the common kestrel is able to coexist with people to some extent and live in their immediate vicinity. However, living in human closeness changes their way of life ${ }^{18}$ and nesting close to humans can have other negative effects on populations ${ }^{19}$. For example, there is a possibility that kestrels that nest in cities for a long time have lower genetic variability than their natural relatives, due to the isolation of these populations ${ }^{20}$. Other problems leading to unsuccessful nesting and raising of the nestling include the collection of their eggs and other inappropriate human interventions ${ }^{21}$. The factors that lead to a reduction in the number of common kestrels have been examined by several authors with varying results. Forero et al. ${ }^{22}$ refuted the assumption that the lack of natural habitats and a higher number of competing raptors contributed to the decline in kestrel numbers. Undoubtedly, the common kestrel, like any wild species, is also threatened by other factors that are not caused by humans, such as certain diseases ${ }^{23}$.

In many countries, care for wild animals (usually that are injured by anthropogenic causes) is provided by rehabilitation centres. Their main goal is to cure these animals and release them back to their natural habitat. This effort involves a range of tasks from the first examination after admission to the rehabilitation centre and determination of the prognosis with regard to the animal's condition and welfare during treatment and up to rehabilitation, which increases the chances of its survival after returning to the wild.

\section{Results}

During the period from 2010 to 2019, a total of 12,923 common kestrels were admitted to 34 rehabilitation centres in the Czech Republic, with yearly intake numbers ranging from 911 to 1596 kestrels (Fig. 1). An increasing trend was found in the number of common kestrels admitted to the rehabilitation centres in the Czech Republic during the monitored period $(\mathrm{rSp}=0.7697, P<0.01)$.

The most common reasons for the admission of common kestrels to rehabilitation centres was admission of nestlings (34.70\%), followed by admission due to power line injuries (26.57\%), other injuries (18.13\%), exhaustion, starvation (4.96\%) and admission after collision with road traffic (4.57\%) (Table 1). Other reasons accounted for less than $4 \%$ of admissions each.

Out of the 12,808 kestrels having their stay in the rehabilitation centre terminated in the monitored period, the majority of birds $(81.66 \%)$ died or had to be euthanized in rehabilitation centres (Table 2$)$. Significantly $(P<0.05)$ fewer birds were returned to the wild $(15.90 \%)$. One hundred and fifteen kestrels were still being treated at the end of the monitored period thus they were not included in the outcome analysis.

The kestrels that were subsequently released back to the wild spent a median of 35 days in the rehabilitation centres (Fig. 2). The kestrels that were declared to be incapable of being released to the wild spent a comparable time (median 30 days) in the rehabilitation centres before they were transferred to another facility for permanent captivity. The decision to euthanize usually occurred within the first day (median 0.5 day, range $0.5-332$ days) and deaths in treated birds occurred within 11 days (median 11 days, range $0.5-1,828$ days). There were several cases of birds escaping within the first days after admission. 


\begin{tabular}{|l|l|l|}
\hline \multirow{2}{*}{ Reason for admission } & \multicolumn{2}{|l|}{$\begin{array}{l}\text { Admitted kestrels } \\
\mathbf{n}=12,923)\end{array}$} \\
\cline { 2 - 3 } & Number & $\%$ \\
\hline Nestlings & 4484 & $34.70^{\mathrm{a}}$ \\
\hline Power line injury & 3434 & $26.57^{\mathrm{b}}$ \\
\hline Other injury & 2343 & $18.13^{\mathrm{c}}$ \\
\hline Exhaustion, starvation & 641 & $4,96^{\mathrm{d}}$ \\
\hline Road traffic & 591 & $4.57^{\mathrm{d}}$ \\
\hline Other & 413 & $3.20^{\mathrm{e}}$ \\
\hline Entrapment & 220 & $1.70 \mathrm{f}$ \\
\hline Unnecessary capture & 188 & $1.45^{\mathrm{fg}}$ \\
\hline Incubation & 145 & $1.12^{\mathrm{h}, \mathrm{i}}$ \\
\hline Feather damage & 128 & $0.99^{\mathrm{i}}$ \\
\hline Intrusion & 126 & $0.98^{\mathrm{i}}$ \\
\hline Injury by another animal & 76 & $0.59^{\mathrm{j}}$ \\
\hline Infection & 63 & $0.49^{\mathrm{j}, \mathrm{k}}$ \\
\hline Rail traffic & 26 & $0.20^{\mathrm{l}}$ \\
\hline Gunshot injury & 25 & $0.19^{\mathrm{l}}$ \\
\hline Poisoning & 20 & $0.15^{\mathrm{l,m}}$ \\
\hline
\end{tabular}

Table 1. Number and percentage of the total number of common kestrels admitted to rehabilitation centres from 2010 to 2019 according to the reason for their admission. ${ }^{\mathrm{a}-\mathrm{m}}$ The values with different superscript letters in a column are significantly different $(P<0.05)$.

\begin{tabular}{|l|l|l|}
\hline \multirow{2}{*}{ Outcome } & Kestrels $(\mathbf{n}=\mathbf{1 2 , 8 0 8})$ & \multicolumn{2}{l|}{} \\
\cline { 2 - 3 } & Number & $\%$ \\
\hline Death & 9920 & $77.45^{\mathrm{a}}$ \\
\hline Release & 2037 & $15.90^{\mathrm{b}}$ \\
\hline Euthanasia & 539 & $4.21^{\mathrm{c}}$ \\
\hline Permanent captivity & 173 & $1.35^{\mathrm{d}}$ \\
\hline Unknown & 134 & $1.05^{\mathrm{e}}$ \\
\hline Escape & 5 & $0.04 \mathrm{f}$. \\
\hline
\end{tabular}

Table 2. Number and percentage of the total number of common kestrels admitted to rehabilitation centres in the period from 2010 to 2019 according to the outcome. ${ }^{\text {a-f }}$ The values with different superscript letters in a column are significantly different $(P<0.05)$.

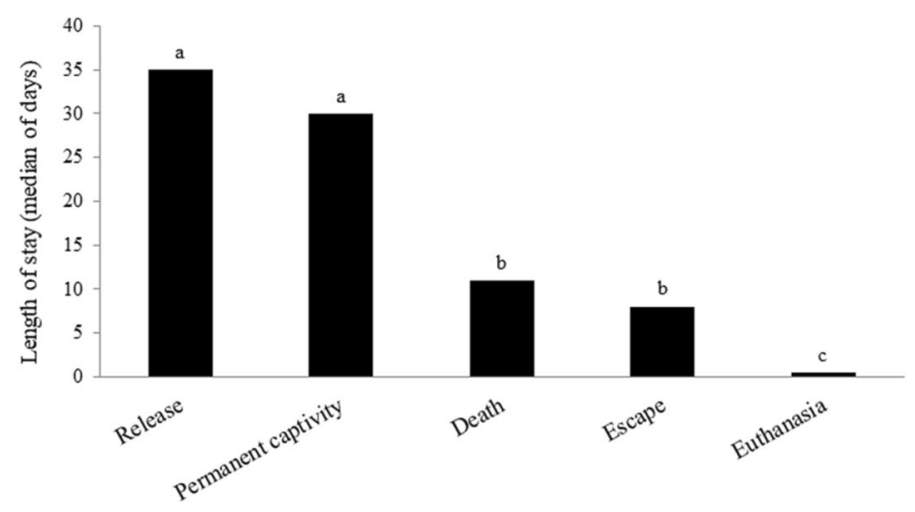

Figure 2. Comparison of the length of stay of common kestrels in rehabilitation centres depending on the outcome. ${ }^{\mathrm{a}-\mathrm{c}}$ The values in columns with different superscript letters are significantly different $(P<0.05)$. 


\begin{tabular}{|l|l|l|l|}
\hline Reason for admission & Number of admitted birds & Number of deaths & Mortality rate (\%) \\
\hline Nestlings & 4484 & 2896 & 64.59 \\
\hline Power line injury & 3434 & 2900 & 84.45 \\
\hline Gunshot injury & 25 & 17 & 68.00 \\
\hline Injury by another animal & 76 & 66 & 86.84 \\
\hline Other injury & 2,343 & 1971 & 84.12 \\
\hline Road traffic & 591 & 528 & 89.34 \\
\hline Rail traffic & 26 & 23 & 88.46 \\
\hline Poisoning & 20 & 20 & 100.00 \\
\hline Infection & 63 & 61 & 96.83 \\
\hline Feather damage & 128 & 98 & 76.56 \\
\hline Exhaustion, starvation & 641 & 534 & 83.31 \\
\hline Entrapment & 220 & 163 & 74.09 \\
\hline Intrusion & 126 & 110 & 87.30 \\
\hline Incubation & 145 & 65 & 44.83 \\
\hline Unnecessary capture & 188 & 145 & 77.13 \\
\hline Other & 413 & 323 & 82.09 \\
\hline
\end{tabular}

Table 3. The number of kestrels that died or had to be euthanized depending on the reason for their admission to rehabilitation centres.

The results show that for almost all reasons for admission to rehabilitation centres, mortality was higher than $50 \%$ (Table 3). In poisoning, mortality was $100 \%$, with none of the poisoned kestrels being saved. There was also a high mortality rate among birds admitted to rehabilitation centres for reasons other than injury or disease, such as unnecessary capture (77.13\%) or feather damage (76.56\%). The highest survival rates were found in nestlings and those hatched in rehabilitation centres, but still their mortality was high ( $64.59 \%$ and $44.83 \%$, respectively).

\section{Discussion}

During the monitored period, an increasing trend was found in the number of admissions of common kestrels to rehabilitation centres in the Czech Republic. However, the question remains whether this is caused by the growing number of injured kestrels in the wild or by the increased public attention to injured animals. There is not enough information to assess this trend. Some authors also found an increasing trend in the number of animals being admitted to rehabilitation centres ${ }^{24-26}$, but some studies have instead found a decreasing trend ${ }^{27,28}$. We can assume that there are differences given the different periods and species observed as well as varying legal regulation of wildlife protection and the people's attitude towards care for disabled wild animals found in the wild.

The reasons for admitting common kestrels to rehabilitation centres in the Czech Republic were very diverse. Most frequently admitted were nestlings (34.70\%) and birds injured by power lines (26.57\%). Similarly, Molina et al. ${ }^{4}$ reported the admission of nestlings as the most common reason for admission (32\%) in a rehabilitation centre in Spain in the period from 1995 to 2007. These nestlings may be brought unnecessarily, as kestrels can nest in the immediate vicinity of humans ${ }^{29}$ and thus arouse their attention or pity. However, these may also be weakened young during periods without plentiful prey, thus reducing the success of nesting and the number of raised nestlings ${ }^{30}$. Kestrels protect their nests ${ }^{31}$, but the presence of humans or noise is stressful and may result in the abandonment of the nests ${ }^{32}$. The negative consequences of noise and other factors related to birds nesting near human dwellings were described by e.g. Baudains and Lloys ${ }^{33}$, French et al. ${ }^{34}$ and Halfwerk et al. ${ }^{35}$.

Worldwide, collisions and electrocution by power lines are responsible for the death of many birds, especially raptors. The number of carcasses near power lines may not accurately reflect the number of birds killed by power lines ${ }^{2}$ because some of the carcasses can be taken away by scavengers ${ }^{36}$. However, a high mortality rate was confirmed by various studies ${ }^{3,37,38}$. The mortality rate can be so high that it affects a population in the area ${ }^{39}$. Over a ten-year period, Rodríguez et al..$^{5}$ observed a raptor rehabilitation centre in Tenerife, where common kestrels predominated among the admitted raptors, and found that various injuries, including collisions with power lines, were the most common reason for admission (42.2\%). The birds that were not killed immediately may be left burned and unable to fly. Power lines, including unsafe power poles, can cause serious injuries to which raptors are particularly susceptible because of specific morphological features (such as their large size and wingspan) and behavior (frequent perching or nesting on power poles) ${ }^{40-42}$. More research is needed on the effects of application of mitigation measures and solutions must be developed on a case-by-case basis ${ }^{43,44}$. Some pylons can cause higher mortality in birds than others, depending on, for example, their height and position ${ }^{45}$ or technical design ${ }^{46}$. Individual measures must also be considered from the point of view of specific species or groups of birds. Differences in perching behavior and possibility of electrocution cause differences in effectiveness of modifications. Insulation of crossarm braces seem to be effective even for the small raptors including kestrels ${ }^{47}$.

Out of the 12,808 common kestrels with known outcomes during the monitored period, 9,920 (77.45\%) birds died and $539(4.21 \%)$ birds had to be euthanized due to incurable conditions or diseases. A successful recovery leading to release of the birds back to the wild was uncommon; it was the outcome for only 2,037 (15.90\%) birds. Interestingly, a considerably higher percentage of released raptors was reported in some other studies. In Jordan, 
between $2017-2018,55.80 \%$ of raptors admitted to a rehabilitation centre were released ${ }^{48}$; in Greece, between $1997-2000,56.90 \%$ of raptors admitted to a clinic were released ${ }^{6}$; in Spain, between $2003-2013,57.57 \%$ of raptors were released ${ }^{49}$; and in Tenerife, between $1998-2007,44.4 \%$ of raptors admitted to a rehabilitation centre were released ${ }^{5}$. In all studies, the total number of raptors was assessed without distinction between various species. Thus, it is not clear how many or if any common kestrels were included and what release rates for individual raptor species were. Furthermore, while the release rates were low for common kestrels in the general wildlife rehabilitation centres operating in the Czech Republic, specialized raptor centres might be more successful when providing treatment to raptors showing the advantage of specialization in rehabilitation centres.

Treatment options for raptors are constantly improving, yet knowledge of the individual requirements of a given species is still very important, along with performing autopsies and identifying the factors that lead to death ${ }^{50}$. Evaluation of blood parameters may be helpful for adjustment of treatment ${ }^{51}$. Prognosis may also be influenced by other factors during the kestrel's life that animal rehabilitation workers are unable to identify. Some studies have addressed the causes of death in raptors, but none focused on species-specific causes. Sara and $\mathrm{Craig}^{52}$, in a rehabilitation centre in Alabama between 1999-2000, reported higher mortality in adult raptors than in young birds. They explain higher mortality in adult birds by older raptors being less tolerant of human handling. Human handling is highly stressful for raptors. As a consequence of stress they may refuse to feed, which further reduces their chances of recovery, especially in the case of long-term captivity ${ }^{53}$. Correspondingly, higher mortality in mature raptors (mortality rate $77.13 \%$ ) admitted to rehabilitation centres including those that were healthy at the time of admission (unnecessary capture) in comparison with nestlings (mortality rate $64.59 \%$ ) was found in our study. Furthermore, Sara and Craig ${ }^{52}$ reported higher mortality in raptor species that are naturally active during the day. They suggest that raptors with diurnal activity are more frequent victims of shooting or road traffic. This may also apply to common kestrels that are diurnal hunters.

The length of stay in the rehabilitation centre differed according to the outcome. Statistically, the kestrels that died or had to be euthanized spent a significantly shorter time in rehabilitation centres than those that were treated successfully and subsequently released. The decision to euthanize was usually made on the day of admission to the rehabilitation centre (median 0.5 days). However, even among the birds that were considered curable and provided with treatment, many of them died within a few days (median 9 days). Molina et al. ${ }^{54}$ found the same length of stay in cases of euthanasia for all animals admitted to a rehabilitation centre in Catalonia. Euthanasia administered shortly after admission is the result of a rapid assessment of the animal's health and its chances of recovery and return to the wild. This rapid decision-making is very important in minimizing the individual's suffering during treatment, especially when treatment success and the animal's return to the wild are uncertain or unlikely ${ }^{55}$. The results of our study, in which only a very small percentage of birds were euthanized compared to the total number of kestrels that died in treatment, suggest that rehabilitation centres in the Czech Republic made greater efforts to rehabilitation kestrels even in the case of an uncertain prognosis. Corresponding to this is the longer time spent in the rehabilitation centre before death found in our study (median 9 days) than found by Molina et al. ${ }^{54}$ in Catalonia (2 days). It remains to be seen whether this approach is appropriate from the point of view of bird welfare. Efforts to rehabilitation animals with a poor prognosis increase their suffering, so it is necessary to consider the benefits of treatment with regard to their welfare, especially for wild animals ${ }^{56}$. The finding of unassisted death being more prevalent than euthanasia was reported also by other studies exploring various species of animals admitted to rehabilitation centres, e.g. reptiles, amphibians, mammals or birds ${ }^{54}$ or hedgehogs ${ }^{27}$. Kelly and Bland ${ }^{28}$ reported the number of individuals that died or were euthanized after unsuccessful treatment (more than 40\%) as comparable to those euthanized upon admission to the rehabilitation centre (approximately 35\%) in Eurasian sparrow hawks (Accipiter nisus) admitted to a rehabilitation centre in England from 2000 to 2004.

Our study revealed that common kestrels admitted to rehabilitation centres had a very high mortality rate overall, almost regardless of the reason for admission. However, some differences in the chance of survival depending on the cause of admission were found. Kestrels admitted due to poisoning seem to have a zero chance of survival, none was rescued during the monitored period. Lead poisoning in raptors is often the consequence of the use of lead ammunition by hunters. Lead bullets are prohibited to be used in waterfowl, but not in other game, and secondary poisoning can occur in kestrels via their prey. For eagles and other raptors, lead is most toxic when consumed, as opposed to lead bullets or shot simply lodging in muscle tissue. Also widespread use of rodenticides is responsible for secondary poisoning to non-target species including raptors. Naldo and Samour ${ }^{57}$ found a high sensitivity to poisoning in the Falconidae family, noting that falcons are more susceptible to ammonium chloride poisoning than, for example, lead poisoning ${ }^{58}$. In our study, very high mortality rates were also found in kestrels admitted due to infectious diseases $(96.83 \%)$, road traffic injuries $(89.34 \%)$ and power line injuries (84.45\%). Molony et al. ${ }^{55}$ also pointed out that mechanical injuries to animals are the most severe and common reasons for euthanasia. Survival can also be affected by finders attempting to take care of the birds on their own ${ }^{59}$. According to the Czech legislation, the care for injured wild animals can be provided only by the competent persons, i.e. persons holding a certificate of competence. Unfortunately, not all people are aware that by law they are obliged to notify the authorized rehabilitation centre in case of finding an injured wild animal and that it is illegal to take such an animal home. However, the results show that not only birds that were admitted to rehabilitation centres due to injury or disease had been dying there. A high mortality rate (77.13\%) was found also in birds that were captured and brought to the rehabilitation centre unnecessarily. 
The results of the study show that the success rate of the care for common kestrels in rehabilitation centres in the Czech Republic during the monitored period was not particularly high. In order to strengthen the protection of kestrels, it is, therefore, essential to primarily focus on their protection in the wild and eliminate factors contributing to the various causes of death and injury. Such measures include the minimization of human interventions in nature, the protection of habitats and the elimination of other risk factors, in particular those related to anthropogenic activity, as they have a major impact on the mortality and morbidity of raptors ${ }^{6}$. As shown by results of our and many other studies, one of the biggest threats to avian species are electric power lines. To reduce risks, it is possible to alter the poles and lines so that they are less dangerous to raptors ${ }^{60}$. The protection of raptors would be improved by greater safety of electrical infrastructure ${ }^{61}$. It is also important to educate the public in order to reduce the number of birds caught unnecessarily or to prevent unprofessional treatment of birds provided by the enthusiastic but incompetent finders. To ensure the successful return of birds from rehabilitation centres to the wild, it is essential to release healthy individuals at suitable locations that increase their survival chances. The time spent in captivity does not seem to impair prey-capture abilities of predation in the common kestrel $^{62}$ yet in many respects, it is useful to monitor survival rates of raptors released after rehabilitation ${ }^{63}$.

\section{Conclusion}

National rehabilitation centre data provide valuable information on the causes of injuries in common kestrels and thus the threats posed by human-altered habitats. Rehabilitation centres generally play an important role in caring for injured, diseased or displaced animals in an effort to release them back to the wild, but the results of our study show that in kestrels, this care is not as successful as in other species. Only a very small portion of the admitted birds could return to the wild. It is therefore essential to focus on prevention, i.e. on factors leading to admission of kestrels to rehabilitation centres. Many kestrels were admitted to rehabilitation centres due to the consequences of anthropogenic activity, especially power line injuries. The technical solutions to this problem already exist, but it is necessary to apply them more widely and effectively. The admission of young kestrels could be often prevented by elimination of human interventions during nesting. Public education is crucial also to avoid unnecessary capture of birds and risks posed to birds by domestic animals, use of chemicals and nettings.

\section{Methods}

The data on common kestrels admitted to rehabilitation centres in the Czech Republic were obtained from the records of the Ministry of the Environment as the central state administrative authority in environmental affairs. The subject of the analysis was the records collected from all rehabilitation centres falling under the National Network of Rehabilitation Centres of the Czech Republic from January 1, 2010 to December 31, 2019. The rehabilitation centres are obligated to provide each injured wild animal found with a complex care routine including first aid, veterinary treatment, therapy and rehabilitation. A handicapped animal is defined by Czech legislation as a wild animal that is temporarily or permanently unable to survive in the wild due to injury, illness or other factors ${ }^{64}$. The records kept by rehabilitation centres contain data on all common kestrels admitted to the rehabilitation centres in the Czech Republic including the reason and date of admission and the outcome for each individual bird. All rehabilitation centres included in the study were general wildlife rehabilitation centres as there are no specialized raptor centres in the Czech Republic. Operation of the rehabilitation centres within the National Network of Rehabilitation Centres of the Czech Republic including the record keeping duty is regulated by the law as they are all state-funded.

For the purposes of statistical evaluation, the kestrels were divided into groups by the year of admission to rehabilitation centres, the reasons for admission to rehabilitation centres and the outcomes. For common kestrels with known admission and discharge dates, the length of stay was also calculated and evaluated.

The categories of the reasons for the admission and outcomes groups correspond to the guidelines for the evidence of admitted animals in rehabilitation centres in the Czech Republic (Table 4). All young birds not yet fledged were included in the 'Nestling ' category, other categories included mature birds only. The categories of outcomes are given in Table 5. Each bird was recorded only in one admission and one outcome group.

We calculated the length of stay of the kestrels in rehabilitation centres as the difference between the date of admission and the date when the stay of a kestrel in the rehabilitation centre was terminated. The kestrels for which the dates were not recorded and those that were still treated in the rehabilitation centre at the end of the monitored period were excluded from this analysis as it was not possible to determine their length of stay. For kestrels which were admitted on the same day as their record was terminated, the length of stay was set to 0.5 days. It is an estimate of the time needed to determine the diagnosis and prognosis (euthanasia, release after treatment, etc.). The median length of stay was calculated separately for each outcome group.

The data were evaluated using the statistical program UNISTAT 6.5 for Excel (Unistat Ltd., London, UK). In assessing the change in the number of recorded common kestrels, we used the Spearman coefficient to determine the coefficient of order correlation. A chi-square test with Yates correction within the methodology of $2 \times 2$ contingency tables was used for statistical evaluation of frequency differences within individual groups with numbers of individuals $>5$. We used the Kruskal-Wallis ANOVA (and multiple comparisons for t-distributions) to statistically compare the length of stay among the individual categories of birds according to their outcome. In the tests used, the value of $P<0.05$ was determined to be statistically significant. 


\begin{tabular}{|c|c|c|}
\hline Reason for admission & Description & Example \\
\hline Nestling & $\begin{array}{l}\text { All young birds that have not reached the age for leaving their nest, not able } \\
\text { to survive on their own }\end{array}$ & Abandoned, orphaned, injured hatchlings or nestlings \\
\hline Power line injury & Injuries caused by the electrical charge from a power line & $\begin{array}{l}\text { Kestrels lying near a power line or found with burn injuries (collisions and } \\
\text { electrocutions) }\end{array}$ \\
\hline Gunshot injury & Injuries caused by rifles, firearms & Gunshot wounds found in the wing etc \\
\hline Injury by another animal & Injuries caused by a bite & $\begin{array}{l}\text { Kestrels admitted after being seen to be attacked e.g. by a dog, suffering } \\
\text { from bite wounds }\end{array}$ \\
\hline Other injury & Other injuries, which were not caused by gunshot, power line or by a bite & Fractures, paralysis etc \\
\hline Road traffic & Kestrels injured by road vehicles & Injured kestrels found on the side of the road \\
\hline Rail traffic & Kestrels injured by rail cars & Injured kestrels found near the railway tracks \\
\hline Poisoning & Kestrels showing signs of poisoning & $\begin{array}{l}\text { Kestrels showing signs of poisoning (e.g. neurological signs after ingestion } \\
\text { of carbofuran), no obvious injuries }\end{array}$ \\
\hline Infection & Kestrels showing the symptoms of infection (including parasite infection) & Symptoms include diarrhea, ruffled feathers, sneezing etc \\
\hline Feather damage & Inability to fly due to the feather damage & E.g. oil contamination \\
\hline Exhaustion, starvation & Dehydration or underweight, no symptoms of infection & Kestrels showing signs of dehydration \\
\hline Entrapment & Kestrels trapped in some way & Kestrels found tangled in nettings or in a chimney \\
\hline Intrusion & Kestrels that invaded a building, namely when they could not get out & Kestrels found in a building \\
\hline Incubation & Kestrels hatched in rehabilitation centres & Incubation of eggs collected from a damaged nest \\
\hline Unnecessary capture & Kestrels (nestlings) brought into the rehabilitation for no apparent reason & $\begin{array}{l}\text { Healthy kestrels showing no signs of injuries or diseases brought into the } \\
\text { rehabilitation centre by a member of the public }\end{array}$ \\
\hline Other & Reasons other than those described above & $\begin{array}{l}\text { E.g. confiscation of illegally kept kestrels, capture of birds escaped from } \\
\text { aviaries or falconers }\end{array}$ \\
\hline
\end{tabular}

Table 4. Reasons for admission of common kestrels to the rehabilitation centres in the Czech Republic.

\begin{tabular}{|l|l|}
\hline Outcome & Description \\
\hline Release & Kestrels that recovered and were released back to their natural habitat \\
\hline Death & Kestrels that died in the rehabilitation centres (unassisted death) \\
\hline Euthanasia & Kestrels euthanized for health reasons by a veterinarian \\
\hline Permanent captivity & Kestrels that had to remain in captivity due to permanent disability \\
\hline Escape & Kestrels that escaped during handling of birds or their treatment or transport in the open air \\
\hline Unknown & Not specified \\
\hline
\end{tabular}

Table 5. Outcomes for common kestrels in the rehabilitation centres in the Czech Republic.

Received: 23 March 2021; Accepted: 13 August 2021

Published online: 26 August 2021

\section{References}

1. McClure, C. J. W. et al. State of the world's raptors: Distributions, threats, and conservation recommendations. Biol. Conserv. 227, 390-402 (2018).

2. Bernardino, J. et al. Bird collisions with power lines: State of the art and priority areas for research. Biol. Conserv. 222, 1-13 (2018).

3. Hager, S. B. Human-related threats to urban raptors. J. Raptor Res. 43, 210-226 (2009).

4. Molina-López, R. A., Casal, J. \& Darwich, L. Causes of morbidity in wild raptor populations admitted at a wildlife rehabilitation centre in Spain from 1995-2007: A long term retrospective study. PLoS ONE 6, e24603. https://doi.org/10.1371/journal.pone. 0024603 (2011).

5. Rodríguez, B., Rodríguez, A., Siverio, F. \& Siverio, M. Causes of raptor admissions to a wildlife rehabilitation centre in Tenerife (Canary Islands). J. Raptor Res. 44, 30-39 (2010).

6. Komnenou, A. T., Georgopoulou, I., Savvas, I. \& Dessiris, A. (2005) A retrospective study of presentation, treatment, and outcome of fre-ranging raptors in Greece. J. Zoo. Wildl. Med. 36, 222-228 (2005).

7. Harris, M. C. \$Sleeman, J. M. Morbidity and mortality of Bald Eagles (Haliaeetus leucocephalus) and Peregrine Falcons (Falco peregrinus) admitted to the wildlife center of Virginia, 1993-2003. J.Zoo Wildl. Med. 38, 62-66 (2007).

8. IUCN Red List. 2020. Common kestrel [online]. [vid. 31st 11. 2020]. Available from: https://www.iucnredlist.org/species/22696 $362 / 93556429$

9. Smallwood, J. A. et al. Why are American kestrel (Falco sparverius) populations declining in North America? Evidence from nestbox programs. J. Raptor Res. 43, 274-282 (2009).

10. Wendell, M. D., Sleeman, J. M. \& Kratz, G. Retrospective study of morbidity and mortality of raptors admitted to Colorado State University Veterinary Teaching Hospital during1995 to 1998. J. Wildl. Dis. 38, 101-106 (2002).

11. Costantini, D., Dell Omo, G., La Fata, I. \& Casagrande, S. Reproductive performance of Eurasian Kestrel Falco tinnunculus in an agricultural landscape with a mosaic of land uses. Ibis 156, 768-776 (2014).

12. Buck, A., Carrillo-Hidalgo, J., Camarero, P. R. \& Mateo, R. Organochlorine pesticides and polychlorinated biphenyls in common kestrel eggs from the Canary Islands: Spatio temporal variations and effects on egg shell and reproduction. Chemosphere 261, 127722; https://doi.org/10.1016/j.chemosphere.2020.127722 (2020). 
13. Wienburg, C. L. \& Shore, R. F. Factors influencing liver PCB concentrations in sparrowhawks (Accipiter nisus), kestrels (Falco tinnunculus) and herons (Ardea cinerea) in Britain. Environ. Pollut. 132, 41-50 (2004).

14. Pain, D. J. \& Amiardtriquet, C. Lead poisoning of raptors in France and elsewhere. Ecotoxicol. Environ. Saf. 25, 183-192 (1993).

15. Newton, I., Wyllie, I. \& Dale, L. Trends in the numbers and mortality patterns of sparrowhawks (Accipiter nisus) and kestrels (Falco tinnunculus) in Britain, as revealed by carcass analyses. J. Zool. 248, 139-147 (1999).

16. Burfield, I. J. The conservation status and trends of raptors and owls in Europe. Ambio 37, 401-407 (2008).

17. González, L. M. et al. Causes and spatio-temporal variations of non-natural mortality in the vulnerable Spanish imperial eagle Aquila Adalbert during a recovery period. Oryx 41, 495-502 (2007).

18. Sumasgutner, P., Schulze, C. H., Krenn, H. W. \& Gamauf, A. Conservation related conflicts in nest-site selection of the Eurasian kestrel (Falco tinnunculus) and the distribution of its avian prey. Landscape Urban. Plan. 127, 94-103 (2014).

19. Sumasgutner, P., Adrion, M. \& Gamauf, A. Carotenoid coloration and health status of urban Eurasian kestrels (Falco tinnunculus). PLoS ONE 13, e0191956. https://doi.org/10.1371/journal.pone.0191956 (2018).

20. Rejt, L., Rutkowvsi, R. \& Gryczynska-Siemiatkowska, A. Genetic variability of urban kestrels in Warsaw - preliminary data. Zool. Pol. 49, 199-209 (2004).

21. Riddle, G. S.The kestrel in Ayrshire 1970-1978. The Journal of the Scottish Ornithologists' Club 10, 200-216 (1979).

22. Forero, M. G., Tella, J. L., Donázar, J. A. \& Hiraldo, F. Canister specific competition and nest site availability explain the decrease of lesser kestrel Falcon populations?. Biol. Conserv. 78, 289-293 (1996).

23. Medica, D. L., Clauser, R. \& Bildstein, K. Prevalence of West Nile Virus antibodies in a breeding population of American kestrels (Falco sparverius) in Pennsylvania. J. Wildl. Dis. 43, 538-541 (2007).

24. Griffith, J. E., Dhand, N. K., Krockenberger, M. B. \& Higgins, D. P. A retrospective study of admission trends of koalas to a rehabilitation facility over 30 years. J. Wildl. Dis. 49, 18-28 (2013).

25. Long, R. B., Krumlauff, K. \& Young, A. M. Characterizing trends in human-wildlife conflicts in the American Midwest using wildlife rehabilitation records. PLoS ONE 15, e0238805. https://doi.org/10.1371/journal.pone.0238805 (2020).

26. Lukesova, G., Voslarova, E., Vecerek, V. \& Vucinic, M. Trends in intake and outcomes for European hedgehog (Erinaceus europaeus) in the Czech rescue centres. PLoS One 16, e0248422; https://doi.org/10.1371/journal.pone.0248422 (2021).

27. Crespo Martínez, J., Izquierdo Rosique, A. \& Surroca Royo, M. Causes of admission and final dispositions of hedgehogs admitted to three Wildlife Rehabilitation Centres in eastern Spain. Hystrix 25, 107-110 (2014).

28. Kelly, A. \& Bland, M. Admissions, diagnoses, and outcomes for Eurasian sparrowhawks (Accipiter nisus) brought to a wildlife rehabilitation centre in England. J. Raptor. Res. 40, 231-235 (2006).

29. Kübler, S., Kupko, S. \& Zeller, U. The kestrel (Falco tinnunculus L.) in Berlin: Investigation of breeding biology and feeding ecology. J. Ornithol. 146, 271-278 (2005).

30. Carrillo, J. \& González-Dávila, E. Impact of weather on breeding success of the Eurasian kestrel Falco tinnunculus in a semi-arid island habitat. Ardea 98, 51-58 (2010).

31. Carrillo, J. \& Aparicio, J. M. Nest defense behavior of the Eurasian kestrel (Falco tinnunculus) against human predators. Ethology 107, 865-875 (2001).

32. Strasser, E. H. \& Heath, J. S. Reproductive failure of a human - tolerant species, the American kestrel, is associated with stress and human disturbance. J. Appl. Ecol. 50, 912-919 (2013).

33. Baudains, T. P. \& Lloyd, P. Habituation and habitat changes can moderate the impacts of human disturbance on shorebird breeding performance. Anim. Conserv. 1, 400-407 (2007).

34. French, S. S., González-Suárez, M., Young, J. K., Durham, S. \& Gerber, L. R. Human disturbance influences reproductive success and growth rate in California Sea Lions (Zalophus californianus). PLoS ONE 6, e17686. https://doi.org/10.1371/journal.pone.00176 $86(2011)$.

35. Halfwerk, W., Holleman, L. J. M., Lessells, C., Kate, M. \& Slabbekoorn, H. Negative impact of traffic noise on avian reproductive success: Traffic noise and avian reproductive success. J. Appl. Ecol. 48, 210-219 (2011).

36. Ponce, C., Alonso, J. C., Argandoña, G., García Fernández, A. \& Carrasco, M. Carcass removal by scavengers and search accuracy affect bird mortality estimates at power lines: Bias sources affecting power-line bird mortality estimates. Anim. Conserv. 13, 603-612 (2010).

37. Lasch, U., Zerbe, S. \& Lenk, M. Electrocution of raptors at power lines in Central Kazakhstan. Waldokologie Online 9, 95-100 (2010).

38. Rubolini, D., Bassi, E., Bogliani, G., Galeotti, P. \& Garavaglia, R. Eagle Owl Bubo bubo and power line interactions in the Italian Alps. Bird Conserv. Int. 11, 19-324 (2001).

39. López-López, P., Ferrer, M., Madero, A., Casado, E. \& McGrady, M. Solving man-induced large-scale conservation problems: the Spanish Imperial Eagle and power lines. PLoS ONE 6, e17196. https://doi.org/10.1371/journal.pone.0017196 (2011).

40. Bevanger, K. Biological and conservation aspects of bird mortality caused by electricity power lines: A review. Biol. Conserv. 86, 67-76 (1998).

41. Janss, G. F. E. Avian mortality from power lines: A morphological approach of a species-specific mortality. Biol. Conserv. 95 , 353-359 (2000).

42. Eccleston, D.T. \& Harness, R. E. Raptor electrocutions and power line collisions in Birds of Prey (ed. Eccleston, D.T. \& Harness, R. E) 273-302 (Sarasola J, Grande J \&Negro J, 2018).

43. Bevanger, K. (2008) Bird interactions with utility structures: Collision and electrocution, causes and mitigating measures. Ibis 136, $412-425$ (2008).

44. Guil, F. et al. Minimising mortality in endangered raptors due to power lines: The importance of spatial aggregation to optimize the application of mitigation measures. PLoS ONE 6, e28212. https://doi.org/10.1371/journal.pone.0028212 (2011).

45. Sergio, F., Marchesi, L., Pedrini, P., Ferrer, M. \& Penteriani, V. Electrocution alters the distribution and density of a top predator, the eagle owl Bubo bubo: Effects of electrocution on eagle owls. J. Appl. Ecol. 41, 836-845 (2004).

46. Mañosa, S. Strategies to identify dangerous electricity pylons for birds. Biodivers. Conserv. 10, 1997-2012 (2001).

47. Guyonne, F. E. \& Ferrer, M. Mitigation of raptor electrocution on steel power poles. Wildl. Society Bulletin 27, 263-273 (1999).

48. Zoubi, M. Y. A., Hamidan, N. A., Baker, M. A. A. \& Amr, Z. Causes of raptor admissions to rehabilitation in Jordan. J. Raptor Res. 54, 273-278 (2020).

49. Montesdeoca, N., Calabuig, P., Corbera, J. A., Rocha, J. \& Orós, J. Final outcome of raptors admitted to the Tafira Wildlife Rehabilitation Centre, Gran Canaria Island, Spain (2003-2013). Anim. Biodivers. Conserv. 40, 211-220 (2017).

50. Cooper, J. E. Raptor care and rehabilitation: precedents, progress and potential. J. Raptor Res. 21, 21-26 (1987).

51. Lam, S. W., Leenen, L. P. H., van Solinge, W. W., Hietbrink, F. \& Huisman, A. Evaluation of hematological parameters on admission for the prediction of 7-day in-hospital mortality in a large trauma cohort. Clin. Chem. Lab. Med. 49, 493-499 (2011).

52. Sara, R. \& Craig, G. A. A retrospective study of mortality and rehabilitation of raptors in the southern United States. J. Raptor Res. 38, 77-81 (2004)

53. Goldberg, H. K. Hearing impairment: a family crisis. Soc. Work Health Care 5, 33-40 (1979).

54. Molina-López, R. A., Mañosa, S., Torres-Riera, A., Pomarol, M. \& Darwich, L. Morbidity, outcomes and cost-benefit analysis of wildlife rehabilitation in Catalonia (Spain). PLOS ONE 12, e0181331. https://doi.org/10.1371/journal.pone.0181331 (2017).

55. Molony, S.E., Baker, P. J., Garland, L., Cuthill, I. C. \& Harris, S. 2007. Factors that can be used to predict release rates for wildlife casualties. Anim. Welfare 16, 361-367 (2007). 
56. Kirkwood, J. \& Best, R. Treatment and rehabilitation of wildlife casualties: legal and ethical aspects. Practice 20, 214-216 (1998). 57. Naldo, J. L. \& Samour, J. H. Causes of morbidity and mortality in falcons in Saudi Arabia. J. Avian Med. Surg. 18, 229-241 (2004).

58. Pain, D. J., Mateo, R. $\$$ Green, R. E. Effects of lead from ammunition on birds and other wildlife: A review and update. Ambio 48, 935-953 (2019).

59. Thompson, L. J., Hoffman, B. \& Brown, M. Causes of admissions to a raptor rehabilitation centre in KwaZulu-Natal South Africa. Afr. Zool. 48, 359-366 (2013).

60. Tintó, A., Real, J. \& Mañosa, S. Predicting and correcting electrocution of birds in Mediterranean areas. J. Wildl. Manage. 74, 1852-1862 (2010).

61. Kemper, M. K., Court, G. S. \& Beck, J. A. Estimating raptor electrocution mortality on distribution power lines in Alberta Canada. J. Wildl. Manage. 77, 1342-1352 (2013).

62. Csermely, D. Duration of the rehabilitation period and familiarity with the prey affect the predatory behavior of captive wild kestrels (Falco tinnunculus). B. Zool. 60, 211-214 (1993).

63. Fischer, D., Hampel, M. R. \& Lierz, M. Monitoring of rehabilitated and evaluated grapevine medium Telemetry as success control. Tierarztl. Prax. K. H. 42, 29-35 (2014).

64. Republic, C. Act on the protection of animals against cruelty. Collection of Law. 50, 1284-1290 (1992).

\section{Author contributions}

G.L. designed the study, collected and organised data and prepared a draft manuscript text. M.V. analysed the data statistically and discussed the results. E.V. and V.V. finalized the manuscript text. All authors reviewed the manuscript and approved the final version.

\section{Funding}

This study was supported by ITA VFU Brno (Project No. FVHE/Vecerek/ITA2020).

\section{Competing interests}

The authors declare no competing interests.

\section{Additional information}

Correspondence and requests for materials should be addressed to G.L.

Reprints and permissions information is available at www.nature.com/reprints.

Publisher's note Springer Nature remains neutral with regard to jurisdictional claims in published maps and institutional affiliations.

Open Access This article is licensed under a Creative Commons Attribution 4.0 International License, which permits use, sharing, adaptation, distribution and reproduction in any medium or format, as long as you give appropriate credit to the original author(s) and the source, provide a link to the Creative Commons licence, and indicate if changes were made. The images or other third party material in this article are included in the article's Creative Commons licence, unless indicated otherwise in a credit line to the material. If material is not included in the article's Creative Commons licence and your intended use is not permitted by statutory regulation or exceeds the permitted use, you will need to obtain permission directly from the copyright holder. To view a copy of this licence, visit http://creativecommons.org/licenses/by/4.0/.

(C) The Author(s) 2021 